\title{
Update on the use of pramipexole in the treatment of Parkinson's disease
}

\author{
Radu Constantinescu \\ Department of Neurology, \\ Sahlgrenska University Hospital, \\ 4 I3 45 Göteborg, Sweden
}

Correspondence: Radu Constantinescu Department of Neurology, Sahlgrenska University Hospital, 4I3 45 Göteborg, Sweden

Tel +46 3I 292537

Email radu.constantinescu@vgregion.se

\begin{abstract}
Pramipexole is a non-ergot dopamine agonist shown to be efficacious in the treatment of Parkinson's disease (PD). This review addresses the literature concerning pramipexole's efficacy in treating motor and non-motor symptoms in PD, its impact on the development of dyskinesias and response fluctuations, the issue of neuroprotection, and the risk for developing adverse events such as increased somnolence, attacks of sudden onset of sleep, cardiac valvulopathy and impulse control disturbances.
\end{abstract}

Keywords: pramipexole, Parkinson's disease, efficacy, adverse events

\section{Parkinson's disease}

Parkinson's disease (PD) is the most common neurodegenerative movement disorder, affecting almost $1 \%$ of the population above the age of 60 years. Its early manifestation is parkinsonism, a progressive impairment of movement control including rigidity, rest tremor, and bradykinesia, while postural instability is a later feature. Non-motor symptoms caused by autonomic disturbances, dysregulation of mood and sleep, changes in cognition and behavior, are present throughout the course of the disease and may become, in advanced stages, the most important cause of disability.

\section{Introduction to the dopaminergic treatment of Parkinson's disease Levodopa}

The most effective and widely used drug in PD is still levodopa, metabolized to dopamine in the brain. During the early phases, motor symptoms in PD respond generally well to levodopa treatment. With advancing disease, treatment related complications such as response fluctuations ("wearing off", "on-off"), motor disturbances (dyskinesias, "off” dystonia), neuropsychiatric side effects (hallucinations, delusions, confusion), and diminished response to levodopa, emerge as major causes of disability.

\section{Dopamine agonists}

The levodopa related complications prompted the development of alternative antiparkinsonian drugs, such as cathecolamine-O-methyl-transferase inhibitors, monoamineoxidase-B inhibitors, and the synthetic dopamine agonists (DA). The DA present several advantages over levodopa such as direct stimulation of striatal dopaminergic neurons, longer half-life providing a more continuous stimulation at the dopamine receptors, lack of oxidative metabolites, more reliable absorption and transport.

DA have been shown to be effective in PD, both as monotherapy and as adjuvants to levodopa (Cotzias et al 1975; Kartzinel et al 1976; Libman et al 1987; Ahlskog et al 1994; Rinne et al 1997; Brooks et al 1998; Parkinson Study Group 2000; Poewe and Wenning 2000). 


\section{Pramipexole in Parkinson's disease}

This review will present the DA pramipexole in the treatment of $\mathrm{PD}$, focusing on the latest developments.

\section{Pharmacodynamics}

Pramipexole is a non-ergotamine full agonist at the D2 subfamily of dopamine receptors, with higher selectivity for D3 than for D2 and D4 dopamine receptors (Mierau and Schingnitz 1992; Svensson et al 1994; Mierau 1995; Mierau et al 1995; Bennett and Piercey 1999). Thereby, pramipexole is able to simultaneously excite the direct striatopallidal pathway (by D3 stimulation) and to inhibit the indirect striatopallidal pathway (by D2 stimulation), alleviating PD symptoms by mimicking dopamine's effects in the striatum. Since the D3 receptors enjoy greatest predominance in the limbic system (Bouthenet et al 1991), pramipexole has the theoretical potential to also have an impact on psychiatric symptoms in PD (Bennett and Piercey 1999). In addition, pramipexole has a very low affinity for 5-HT2A, 5-HT2B, and D1 receptors, partly explaining its beneficial effects in the context of cardiac valvulopathy and dyskinesias, as discussed later.

\section{Pharmacokinetics}

Pramipexole has an absolute oral bioavailability greater than $90 \%$, indicating good absorption and little first pass metabolism. It exhibits linear pharmacokinetics and less than $20 \%$ is protein bound; more than $90 \%$ of the absorbed dose is eliminated unchanged and almost exclusively by the kidneys, motivating a dose reduction with low creatinine clearance. Its elimination half-life is 8 hours in young, healthy volunteers (Häselbarth 1994a, b; Wright et al 1997; Bennett and Piercey 1999).

In men and postmenopausal women with $\mathrm{PD}$, gender had no impact on the pharmacokinetics of pramipexole, and pramipexole did not alter levodopa's bioavailability (Kompoliti et al 2002).

In contrast to other DA, pramipexole has been found to exert no strong cytochrome P 450 inhibition in vitro, minimizing the risk for drug-drug interactions (Wynalda and Wienkers 1997).

\section{Clinical efficacy}

\section{Monotherapy in early Parkinson's disease}

Summary of previous results: The safety and efficacy of pramipexole as monotherapy in early PD were originally evaluated in 2 placebo-controlled clinical trials enrolling 599 PD subjects (Parkinson Study Group 1997; Shannon et al 1997). In addition, the Comparison of the Agonist Pramipexole with Levodopa on Motor Complications of PD (CALM-PD) study, conducted by the Parkinson Study Group (PSG), investigated initial treatment with pramipexole vs initial treatment with levodopa in 301 patients with early PD, requiring dopaminergic therapy. The subjects were randomly assigned to receive $1.5 \mathrm{mg}$ pramipexole or $300 \mathrm{mg}$ levodopa daily. The two treatment groups were of equal size. After the first 10 weeks of treatment, open-label levodopa (and during the last year of the study also other antiparkinsonian medication) could be added as needed, for better symptom control (Parkinson Study Group 2000). The CALM-PD study design and the subsequent long follow up (up to 58 months), generated a wealth of data regarding the effects of pramipexole on a variety of PD features.

The combined results of these three pivotal studies showed that pramipexole, started at low initial doses and up-titrated weekly, was effective and well tolerated in mild to moderate PD. No differences in effectiveness based on age or gender were detected, and no dose-response relationship could be demonstrated. Thus, doses of $1.5 \mathrm{mg}, 3 \mathrm{mg}, 4.5 \mathrm{mg}$, and $6 \mathrm{mg} /$ day did provide similar significant benefit in reducing PD signs and symptoms compared with placebo. However, several side effects were dose related. On the Unified Parkinson's Disease Rating Scale (UPDRS) (Lang 1989) significant improvement from baseline could be seen in both section II (around 2 points), and section III (around 5 points), compared with placebo ( $<0.6$ points on both sections).

New studies: The 4-year results of the CALM-PD study showed that, after 4 years, initial treatment with pramipexole resulted in a significant reduction of the risk for developing treatment fluctuations and dyskinesias but in a higher risk for freezing, vs initial treatment with levodopa. On the other side, a greater improvement in the total UPDRS score was seen in the levodopa group vs the pramipexole group ( $2 \pm$ 15.4 points vs $-3.2 \pm 17.3$ points). More patients in the pramipexole group needed at 4 years open-label levodopa vs the levodopa group ( $72 \%$ vs $59 \%$ ) but the mean daily levodopa dose was lower in the pramipexole group $(434 \pm 498 \mathrm{mg}$ /day vs $702 \pm 461 \mathrm{mg} /$ day). More pramipexole patients withdrew prior to the final follow-up visit than levodopa patients ( $45 \%$ vs $33 \%$ ) due to side-effects (Holloway et al 2004).

\section{Adjuvant therapy in advanced Parkinson's disease}

Summary of previous results: Several clinical trials examined the medium and long term efficacy of pramipexole at a maximal dosage of $4.5 \mathrm{mg}$ daily, as an adjuvant to levodopa therapy in moderate to advanced PD. The combined results 
showed that pramipexole was well tolerated, associated with a reduction in daily L-dopa usage, and in daily "off" time, together with improvement in several parkinsonism and disability scorings (Lieberman et al 1997; Bennett and Piercey 1999; Pinter et al 1999, 2000; Weiner et al 2001).

New studies: Möller et al reported 2005 on 354 levodopatreated PD patients with motor fluctuations. A first, doubleblind, placebo controlled phase of 32 weeks was followed by an open-label phase with a maximum duration of 57 months. Pramipexole was administered t.i.d. at a total daily dosage varying between 0.375 and $4.5 \mathrm{mg}$. The effect emerged at a daily dose of $0.75 \mathrm{mg}$. The levodopa dosage could be decreased in $39 \%$ of the pramipexole treated patients vs in $12.8 \%$ of the placebo group. Pramipexole as an adjuvant therapy was found to be superior to placebo and effective at reducing UPDRS sum scores of parts II and III by 30\%, and "off time" by 2.5 hours/day. Improvement was also seen on UPDRS part I through the items motivation/initiative and depression, but not intellectual impairment and thought disorder. Overall, pramipexole had a better anti tremor effect than placebo (change -2.5 and -0.5 respectively on the sum of UPDRS tremor-related items). Tremor was considered prominent when the baseline sum score of UPDRS III tremorrelated items was at least 8 ( 6 if unilateral tremor) or the relative contribution of tremor items to the total UPDRS II and III score was $>20 \%$. Patients with prominent resting tremor benefited more from pramipexole than from placebo. Thus, the mean (SD) decrease in the total tremor score in the high tremor score group was 8 (4.2) for pramipexole compared with 3.7 (5.7) for placebo. The prevalence of somnolence was low ( $1.7 \%$ in the pramipexole group vs 2.2 in the placebo group), but this symptom was not specifically asked for, just recorded if spontaneously reported. There were more dyskinesias and visual hallucinations in the pramipexole group vs the placebo group (30\% vs $8.7 \%$, and $11.1 \%$ vs $4.4 \%$ respectively). During the double-blind phase, totally $27 \%$ of all patients $(17.8 \%$ in the pramipexole group and $36.1 \%$ in the placebo group) had an adverse event that led to the discontinuation of the study medication, most frequently due to aggravated parkinsonism. During the open-label phase, $23.7 \%$ of all subjects had an adverse event that led to discontinuation of study medication, most often aggravated parkinsonism, visual hallucinations, and dyskinesias. Pramipexole's long-term efficacy and tolerability were good (Moller et al 2005).

Two studies examined pramipexole's efficacy in other ethnical groups than Caucasians. The first, a 15-week-long, randomized, double-blind, placebo-controlled, parallel-group study, was conducted in Hong Kong and Taiwan in 150 untreated and levodopa-treated Chinese patients with both early and advanced PD (Wong et al 2003). Pramipexole, both as monotherapy and as adjuvant to levodopa, was found to be more effective than placebo for symptom reduction measured with UPDRS Part I, Part III, and Parts I plus III. Pramipexole addition to levodopa led to a decrease in the number of "off" hours per day from 7.07 to 6.15 hours/day. In the placebo group the "off" time increased from 5.59 to 6.87 hours/day. Slightly more adverse events were reported overall for pramipexole treated patients $(86 \%)$ compared with the placebo group (71\%), with the largest differences for constipation, nausea, dry mouth, dyskinesias, somnolence and hallucinations. Interestingly, more tremor was reported in the placebo group (11.7\%) compared with the pramipexole group $(1.4 \%)$, possibly indicating a more specific antitremor effect for pramipexole.

The results of the second study were published recently. In a 10 weeks long, double-blind, randomized, placebocontrolled trial, pramipexole was administrated as an adjuvant therapy to 144 levodopa-treated PD patients of African American, Asian, and Hispanic heritage (Parkinson Study Group 2007). Overall, pramipexole was found to have a similar efficacy in all ethnical groups, and of the same magnitude as shown in former trials on primarily nonHispanic whites. African Americans showed a statistically significant improvement in tremor measured by UPDRS part 3 tremor subscales. The overall tolerability and safety were also similar across the ethnical lines, but with different profiles in the different groups. More patients of Asian heritage reported asthenia compared with African Americans and Hispanics, while confusion was more frequent in the African heritage group. Hallucinations and insomnia were more common with pramipexole than with placebo. No sleep attacks were reported. Premature withdrawals occurred 3 times more frequently in persons of African heritage than in Asians, usually due to comorbid illnesses. These differences were not statistically significant but may indicate the need of more research in this field. A pharmacokinetic substudy on 40 patients did not show any differences in the pharmacokinetic profile among the ethnic groups.

\section{Comparative studies}

Rotigotine: In 506 subjects with advanced PD already treated with levodopa and other antiparkinsonian drugs, pramipexole was compared with rotigotine patch and placebo, as adjuvants. Primary efficacy variables were absolute change in total hours "off" from baseline to end of study, as recorded by patients on home diaries, and responder rate, defined as 
the proportion of patients with a $30 \%$ or more reduction in absolute off time per day. Both active therapies showed similar efficacy in respect to both primary and secondary response parameters, and were superior to placebo. Responder rates and reduction in off-time were in absolute numbers somewhat higher for pramipexole, but not enough to show any statistically significance. Both pramipexole and rotigotine showed good tolerability, with more reports of hallucinations, dyskinesias and dizziness in the pramipexole group, and more reports of nausea and application site reactions in the rotigotine group (Poewe et al 2007).

Bromocriptine: Pramipexole was compared with bromocriptine and placebo as adjuvant therapy in 325 patients with advanced PD. The primary end points were the change from baseline to study termination on UPDRS parts II and III. The magnitude of the observed changes on the primary endpoints was larger, the response came earlier, and the improvement from baseline to each subsequent visit was greater in the pramipexole group compared with bromocriptine, throughout the treatment. Statistically, the two treatment groups were similar, presumably due to an insufficient number of patients and low power. Both active treatments showed the same rate of responders and the rate of adverse events was similar for all 3 groups. Overall, pramipexole was shown to be clearly superior to placebo and not inferior to bromocriptine (Mizuno et al 2003).

Guttman et al compared adjuvant therapy with pramipexole and placebo in PD patients with a declining response to levodopa, including a bromocriptine group for comparison with placebo. The primary end points were UPDRS parts II and III. They found no differences in efficacy and adverse events between pramipexole and bromocriptine but the study was not powered for detecting any. Both DA were superior to placebo (Guttman 1997).

Pergolide: Rektorová et al found no significant differences between pramipexole and pergolide as add-on therapies to levodopa in advanced PD patients with depression, as measured on UPDRS scales (Rektorova et al 2003).

In an open label study including 25 patients, Hanna et al found no significant difference in the efficacy of pramipexole vs pergolide as adjuvant therapies in mild to moderate PD, although there was a slight trend in favour or pramipexole (Hanna et al 2001).

Mixed: Goetz et al investigated slow (over 8 weeks) vs rapid (over 1 day) switch from bromocriptine/pergolide to pramipexole in $16 \mathrm{PD}$ patients on stable levodopa therapy. The primary outcome was the time required to achieve a UPDRS motor score superior to baseline without increased side effects.
The conversion rate to pramipexole was $1: 1$ for pergolide and 1:10 for bromocriptine. They found that a rapid titration based upon an equivalency dose calculation was preferable. Pramipexole was superior to both pergolide and bromocriptine in respect to motor UPDRS scores (Goetz et al 1999).

Reichmann et al conducted a study in 1202 PD patients who were switched slowly or quickly to pramipexole from any other oral DA, as add-on therapy, because of insufficient effectiveness on motor performance, tremor, and mood (depression, anhedonia). The switch to pramipexole led to improvement of all symptoms. Resting tremor improved more than postural tremor. No difference was found between either switching procedure in respect to clinical efficacy, tolerability, and safety. Most patients tolerated pramipexole better or equally well, compared with their previous DA (Reichmann et al 2006).

An analysis of 7 trials on pramipexole, ropinirole, pergolide, entacapone and tolcapone as add-on therapies to levodopa in PD found that pramipexole and entacapone were the best choices for obtaining a greater reduction in levodopa dose and in "off" time, and a better tolerability. All active drugs caused about the same amount of dyskinesias except higher dose tolcapone (600 mg) which caused more dyskinesias (Inzelberg et al 2000).

In conclusion, most data suggest that pramipexole and the other DA are similarly efficacious as adjuvant therapy to levodopa in advanced PD.

\section{Specific symptoms}

\section{Drug-resistant tremor in Parkinson's disease}

Parkinsonian tremor can occasionally be unresponsive to dopaminergic therapy and notoriously difficult to treat.

Navan et al conducted a randomized, double-blind, 3-month parallel study in 30 PD patients, most of whom were already medicated. The aim was to investigate the effects of pramipexole, pergolide, and placebo on parkinsonian tremor. They found that both pergolide and pramipexole had significantly better overall antitremor effect than placebo, and their efficacy was similar. However, pergolide was superior to pramipexole in alleviating rest tremor and postural tremor scored clinically. Both drugs had similar beneficial effects on the UPDRS motor subscores and the tolerability was better for pramipexole (Navan et al 2003b). The same group did also report a similar but modest reduction in rest tremor with a single $500 \mu \mathrm{g}$ dose of either pramipexole or pergolide, compared with placebo (Navan et al 2003a).

Pogarell et al investigated 84 early and advanced PD patients with marked drug-resistant tremor under a stable 
and optimized antiparkinsonian medication. Pramipexole or placebo were administered as add on medication. The primary end point was the absolute change in tremor score, defined as the sum of UPDRS tremor related items $(16,20,21)$ in "on" periods. Pramipexole was found to be significantly superior to placebo with a difference between treatment groups in the mean absolute change in tremor score of -4.4 points ([95\% CI] -6.2 to $-2.5 ; \mathrm{p}<0.0001)$, corresponding to a difference in the mean percentage change of $-34.7 \%$ in favor of pramipexole (Pogarell et al 2002).

In conclusion, existing data suggest that pramipexole may be effective for treating drug-resistant tremor in PD.

\section{Non-motor symptoms in Parkinson's disease}

In addition to the noticeable motor symptoms, less obvious and sometimes more difficult to treat non-motor symptoms may greatly increase the distress and disability in PD. Increasing evidence supports pramipexole's efficacy in ameliorating some of these symptoms.

Depression: In non-PD patients with both unipolar and bipolar major depression, pramipexole was shown to be effective in alleviating depressive symptoms, in monotherapy or as an adjuvant (Corrigan et al 2000; Lattanzi et al 2002; Goldberg et al 2004). Depression and other psychiatric disorders affect up to 50\% of all PD patients (Dooneief et al 1992; Tandberg et al 1996) with negative impact on motor-related disability and quality of life (QOL) (Schrag et al 2000).

In a randomized trial from 2005 including 67 PD patients with major depression and without motor complications, pramipexole was compared with sertraline in respect to recovery from depression, defined as a final HAM-D (Hamilton 1960) score $\leq 8$ (Lemke et al 2006). Pramipexole led to recovery in $60.6 \%$ of patients, which was significantly higher compared with sertraline (27.3\%). However, there was no difference between the two treatments when depression was assessed with Zung self-relating depression score (Zung 1965). There were more adverse effects in the sertraline recipients, responsible for a $15 \%$ withdrawal from the study (5 patients). None of the 33 pramipexole patients withdrew. In the pramipexole group there was a significant improvement in motor symptoms as measured by UPDRS part III. A noticeable limitation of the study was the lack of a placebo group, given that there is a high degree of placebo response in depressed PD patients (Weintraub et al 2005).

A randomized, open-label, comparative study investigated the effect of adjuvant therapy with pramipexole and pergolide in 41 non-demented, levodopa-treated PD patients, all of which had motor complications, including fluctuations and dyskinesias. About a third of the patients in each DA group had mild to moderate depression at baseline. A significant decrease of Zung depression score (Zung 1965) was reported for both DA, but improvement on MontgomeryÅsberg Depression Rating Scale (Montgomery and Asberg 1979) was seen only among the pramipexole recipients. At the same time, pramipexole improved motor symptoms including motor complications, and this may also have been a cause for improved depression, although pramipexole was superior even when controlling for the motor improvement. There was no significant difference between pramipexole and pergolide as adjuvant in respect to motor symptoms, activities of daily living, and treatment complications. The daily levodopa dose could be significantly decreased, more so in the pergolide group (Rektorova et al 2003).

In conclusion, existing data suggest that pramipexole may play a role in reducing symptoms of depression in PD.

Anhedonia: An observational study on 657 PD patients in early and advanced disease stages (Hoehn and Yahr 1-5 [Hoehn and Yahr 1967]) found that pramipexole as add-on to levodopa therapy improved anhedonia, the reduced capacity to experience pleasure, as evaluated by the Snaith-Hamilton Pleasure Scale (Snaith et al 1995). Notably, this was seen in both depressed and in non depressed PD patients, and was therefore not only due to an antidepressant effect. Meanwhile, in line with the results of other studies, it was seen that severe, moderate, and mild depression also decreased (Reichmann et al 2003; Lemke et al 2005; Lemke et al 2006).

Cognition: Cognitive impairment is common in PD, and up to a third of PD patients develop overt dementia (Aarsland et al 2005). As results from studies in healthy controls suggest that pramipexole may worsen cognitive abilities (Pizzagalli et al 2007), it is important to investigate its impact on cognition in PD.

Rektorová et al examined in a randomized study the effects of pramipexole and pergolide as adjuvant therapy to levodopa in 41 non-demented patients with advanced PD and a current depressive episode. While confirming that pramipexole had an antidepressant effect and that both DA improved motor performance, the results showed no significant effect on the neuropsychological tests applied. The conclusion was that both pramipexole and pergolide as adjuvant therapy to levodopa are safe in terms of effects on cognitive performance (Rektorova et al 2005).

Relja et al evaluated over 6 months the effects of pramipexole as add-on therapy in PD patients treated with levodopa. An exclusion criterion was evidence of possible dementia and only patients scoring above 25 on the 
mini-mental state examination (MMSE) were included. They found no statistically significant difference in performance on the cognitive tests applied, between those treated with levodopa in monotherapy and those adding pramipexole, but there was a trend for a greater decline on Letter Fluency (Benton 1989) and Trail Making test (Reitan 1992) in the latter group (Relja and Klepac 2006).

Brusa et al investigated in a randomized study 20 patients with early/mild PD treated with levodopa or with pramipexole. Patients with dementia were excluded. They found that pramipexole but not levodopa produced a significant impairment of short term verbal memory, attentional-executive functions, and verbal fluency (Brusa et al 2003).

Given the fact that cognitive impairment is common in advanced PD, it would be of great interest to know more about pramipexole's effects in a cognitively impaired PD population. In the previously mentioned studies, no demented PD subjects were included and no studies on pramipexole in a cognitively disabled $\mathrm{PD}$ population could be identified. A case report regarding an 85 years old demented lady with parkinsonism indicated that pramipexole might have contributed to a worsening of the patient's cognition and general condition (Scoyni et al 2007). As cognitive decline is more common with advancing age and disease stage in $\mathrm{PD}$, the results of one study on the use of DA in very elderly patients with PD are especially interesting in this context (Shulman et al 2000). In total, 43 non-demented PD patients (24 between 80 and 85, 14 between 86 and 90, and 5 between 91 and 95 years of age), with a mean disease duration of 11 years, were treated with pramipexole (mean daily dose $2.7 \mathrm{mg}$ ). The overall success rate over a mean treatment time of 14 months was $40 \%$ (17 of 43 patients). The adverse effect event rate was of the same magnitude as in younger patients (around 60 years old), and the adverse events profile was similar with that reported in younger patients, with the exception of hallucinations, which were more common in this very old age group. Thus $21 \%$ of the patients treated with pramipexole reported hallucinations. Unfortunately, the design of the study did not provide any specific data on cognition and the effects of pramipexole therapy.

Biglan et al found that better cognitive function defined as MMSE > 28 was associated with a decreased risk for developing hallucinations after pramipexole therapy in PD (Biglan et al 2007).

In the light of the aforementioned results and especially considering the higher risk for hallucinations with pramipexole therapy, there is reason to suspect that pramipexole may have deleterious effects on cognition in an advanced PD population showing cognitive deficits.

In conclusion, there are mixed results in respect to pramipexole's impact on cognition in a non-demented PD population, with studies showing no deleterious effects and studies suggesting cognitive worsening. No studies suggesting that pramipexole treatment may lead to an improvement in cognition were identified. Although no studies examining the effects of pramipexole in a cognitively impaired PD population could be found, caution is recommended in this respect.

Apathy: Apathy is a frequent finding in PD, significantly associated with cognitive impairment, executive dysfunction, anxiety and depression (Starkstein et al 1992; Aarsland et al 1999; Pluck and Brown 2002). Apathy levels in PD are higher than in equally disabled patients with other diagnoses (Pluck and Brown 2002). While apathy does not seem to respond to levodopa, there are some indications from clinical trials that pramipexole's D3 agonist properties may be beneficial in this respect (Guttman and Jaskolka 2001; Kumru et al 2006).

\section{Miscellaneous symptoms}

Restless legs syndrome: There may be an overrepresentation of restless legs syndrome (RLS) in PD and the relationship between the two diseases is not completely elucidated (Poewe and Hogl 2004). Pramipexole has been shown to be effective in treating pure RLS (Montplaisir et al 1999), as well as other DA, but no studies investigating pramipexole's efficacy in the treatment of RLS in PD patients have been identified.

Weight loss: Weight loss is seen in PD patients already before diagnosis and continues throughout the course of the disease. Possible causes include: (1) increased energy expenditure due to increased muscular activity (rigidity, dyskinesias); (2) decreased energy intake, due to general movement impairment (difficulties in feeding, accessing food, and swallowing), and decreased appetite caused by depression; and (3) an inherent metabolic abnormality in PD (Chen et al 2003; Lorefalt et al 2006; Toth et al 1997). Increased body weight, as well as motor and mood improvement, were seen in 28 non-depressed, advanced PD patients on stable medication, 3 months after starting treatment with pramipexole (Kumru et al 2006). In addition, many patients treated with pramipexole reported a decrease in anxiety and apathy together with enhanced attention span and interest in daily activities. No patient reported dysphagia, vomiting or changes in eating behavior but 12 reported increased hunger. There was no relationship between changes in BMI and in UPDRS part III and the authors speculate that the weight 
increase was due to a direct or indirect action of pramipexole on the feeding centers in the hypothalamus.

Rapid eye movement (REM) sleep behavior disorder (RBD): Rapid eye movement (REM) sleep behaviour disorder (RBD) may involve a dopaminergic deficiency, as it is associated with both PD and RLS. The traditional first-line therapy for RBD is clonazepam. Nevertheless, 2 studies were found that reported on pramipexole in RBD, although none was directed at PD patients.

Fantini et al reported about 8 patients with idiopathic $\mathrm{RBD}$, treated with pramipexole, 7 of which experienced a reduction in the frequency and intensity of RBD. In 5 patients this reduction was sustained (Fantini et al 2003).

Schmidt et al reported about 10 patients with RBD, 3 of which had parkinsonism. Pramipexole reduced markedly the frequency and severity of RBD in $89 \%$ of the patients (Schmidt et al 2006).

The results of these studies are interesting but they have to be replicated in a PD population before gaining any acceptance in the treatment of PD related RBD.

Fatigue: Fatigue is an early symptom in some PD patients (Schifitto 2006). While fatigue improved in patients with fibromyalgia with pramipexole treatment (Holman and Myers 2005), it was reported as an adverse event in PD patients treated with pramipexole (Pinter et al 1999; Pogarell et al 2002).

\section{Dopaminergic complications in Parkinson's disease}

The risk of experiencing response fluctuations (wearing off, on-off) or dyskinesias in PD has been evaluated at $40 \%$ after about 5 years of levodopa treatment (Ahlskog and Muenter 2001).

The CALM-PD study examined the risk for developing dopaminergic complications in early PD individuals initially treated with pramipexole monotherapy versus levodopa monotherapy. Eventually all patients could add levodopa for emerging disability. After 2 years, $28 \%$ of subjects assigned to pramipexole developed dopaminergic complications vs $51 \%$ in the levodopa group (Parkinson Study Group 2000).

The 4-years results of the CALM-PD study showed that initial treatment with pramipexole vs initial treatment with levodopa resulted in a significant reduction of the risk for developing dyskinesias (24.5\% vs 54\%), and wearing off (47\% vs $62.7 \%$ ), but in a higher risk for freezing $(37.1 \%$ vs $25.3 \%$ ). The occurrence of disabling dyskinesias was uncommon and did not differ between the two treatment groups. The risk for on-off fluctuations was the same in both groups.
Ten patients in the pramipexole group developed dyskinesias prior to the open-label levodopa treatment, 7 of which had never been exposed to levodopa (Parkinson Study Group 2000; Holloway et al 2004). Initial pramipexole treatment was associated with the appearance of motor fluctuations before dyskinesias (Hauser et al 2006).

A comparison of several published studies on the treatment of early PD with levodopa, pramipexole, cabergoline, or ropinirole, showed a reduction in the risk for developing dyskinesias for all three DA compared with levodopa. This reduction was slightly higher for pramipexole and ropinirole compared with cabergoline (absolute risk reductions $20 \%, 25 \%$, and $8 \%$ respectively). These findings are not unexpected, as dyskinesias seem to be mediated by the D1 receptor, for which pramipexole has a very low affinity compared with other compounds, such as cabergoline (Inzelberg et al 2003).

\section{Neuroprotection}

\section{In vitro and in vivo studies}

Pramipexole has been shown to have several neuroprotective actions, presumably through its antiapoptotic, antioxidant, and antitoxic effects, and through induction of neurotrophic factors. In cell cultures pramipexole protected against dopaminergic neuronal death induced by glutamate (Izumi et al 2007), 1-methyl-4-phenylpyridinium (MPP+) (Presgraves et al 2004), 6-hydroxydopamine (6-OHDA) (Le et al 2000), rotenone (Gu et al 2004), L-dihydroxyphenylalanine (L-DOPA), and methamphetamine (Hall et al 1996); in a recent study, pramipexole was shown to prevent neurotoxicity induced by oligomers of beta-amyloid, suggesting that pramipexole may have a role to play also in the treatment of other neurodegenerative diseases related to beta-amyloid proteins (Uberti et al 2007); in a dopaminergic cell line, pramipexole attenuated neurotoxicity induced by dopamine and levodopa, possibly through a mechanism related to antioxidant activity, scavenging of free radicals such as hydrogen peroxide, and inhibition of apoptosis (Zou et al 1999). Pramipexole stimulated the production of a dopaminergic neurotrophic factor in tissue cultures (Carvey et al 2001), and increased the Nurr1 gene expression and protein levels (Pan et al 2005). It has been hypothesized that by suppressing STN overactivity, pramipexole may ameliorate the subthalamicus nucleus mediated excitotoxicity. Finally, pramipexole reduced mitochondrial swelling and could thereby have an antiapoptotic effect (Cassarino et al 1998; Sayeed et al 2006). In mice, pramipexole treatment completely antagonized the neurotoxic effects of MPTP (Joyce et al 2004). 


\section{In humans}

The CALM-PD study attempted to assess pramipexole's neuroprotective effect in humans, by quantifying the rate of decline from baseline in striatal ([123]I)beta-CIT-SPECT uptake, a measure of the density of striatal presynaptic dopaminergic innervation, reflecting the degeneration of substantia nigra. Forty-two PD subjects were randomized to initiate therapy with pramipexole and 40 with levodopa, both as monotherapy. Eventually, both groups could add levodopa when needed. After both 2 and 4 years of treatment, the group initially receiving pramipexole showed a slower rate of decline in striatal ([123]I)beta -CIT SPECT uptake compared with the group initially randomized to levodopa (7.1\% vs $13.5 \%$ at 22 months ( $\mathrm{p}=0.004)$; and $16.0 \%$ vs $25.5 \%$ at 46 months $(\mathrm{p}=0.01)$. In addition, the percentage loss from baseline in striatal ([123]I)beta -CIT uptake was correlated with the change from baseline in UPDRS at the 46-month evaluation $(r=-0.40 ; p=0.001)$ (Parkinson Study Group 2002). The interpretation of these results is equivocal due to the lack of a placebo group, and because it can not be ruled out that the differences in the rate of decline from baseline may be due to direct pharmacological effects of pramipexole on the ligand receptors, and not due to a slowing of the disease process with pramipexole (Ravina et al 2005). Both animal and human studies show for example that short term therapy with pramipexole can down-regulate striatal dopamine transporters (Guttman et al 2001).

The results of a subanalysis of CALM-PD data argue against a neuroprotective action of pramipexole, which, as initial therapy in PD, did not lower the risk for dyskinesias once levodopa was added to the treatment, after controlling for levodopa dose. Nonetheless, pramipexole delayed the point in time when levodopa treatment was needed and thereby delayed also the appearance of dyskinesias (Constantinescu et al 2007).

In conclusion, despite promising results in preclinical studies, there are still no convincing clinical data confirming a neuroprotective effect of pramipexole in PD.

\section{Patient-focused perspective in Parkinson's disease Cost-effectiveness}

Using data from the CALM-PD study, Noyes et al made a cost-effectiveness assessment of initial treatment with pramipexole vs levodopa, in early PD. The results reflecting the first 2 years of treatment suggested that pramipexole was not welfare enhancing due to higher costs compared with levodopa (Noyes et al 2004). However, after 4 years, the cost-effectiveness of pramipexole increased, with the largest incremental benefit being noticed during the fourth year of the trial. The increased effectiveness was not due to a reduction in costs compared with levodopa, but to a greater gain in quality adjusted life years (QUALY). Subjects with lower QOL and more depressive symptoms at baseline showed the highest improvement in QUALY gains over time (Noyes et al 2005).

\section{Quality of life (QOL)}

Health-related QOL (HRQOL) evaluates a person's wellbeing. Several studies have shown that QOL decreases in PD patients as the disease progresses (Karlsen et al 2000). Data from the CALM-PD study was used to compare the effect of pramipexole vs levodopa on disease-specific QOL. Although at 24 months, the levodopa group showed better QOL scores than the pramipexole group (Parkinson Study Group, 2000), there was no difference in the mean changes in the HRQOL between baseline and 48 months follow up (Holloway et al 2004). However, this approach ignored the dynamics of HRQOL changes. Consequently, when taking into account the HRQOL values for all visits and accumulating gains and losses over time, by each treatment arm, a different pattern emerged. During the first year, HRQOL increased, and during years 2-4, it decreased in both arms. The deterioration was greater in the levodopa arm, although, at all times, there was a 5-point UPDRS benefit favoring levodopa, suggesting that pramipexole induced its improvement thorough non-motor and levodopa through motor mechanisms. The difference in HRQOL between the two treatment arms widened in years 3 and 4 in favor of pramipexole suggesting that a longer follow up may show even larger differences. The clinical relevance of these findings is not clear at this time (Noyes et al 2006).

\section{Tolerability and adverse events}

As already discussed in section 3.3, pramipexole is generally well tolerated up to a total daily dose of $4.5 \mathrm{mg}$, both as monotherapy and as an adjuvant to levodopa in PD patients at different disease stages. The highest dosage of $6 \mathrm{mg}$ daily led to a higher incidence of neuropsychiatric side effects, particularly somnolence, and there is generally a direct relationship between pramipexole dose and adverse events. Adverse events that appear to occur more often with pramipexole compared with placebo are sleep disturbances, gastrointestinal symptoms (nausea, constipation), postural hypotension, peripheral edema, impulse control disorders, and hallucinosis (Lieberman et al 1997; Moller et al 2005; 
Parkinson Study Group, 1997; Parkinson Study Group, 2000; Pinter et al 1999; Shannon et al 1997; Weiner et al 2001). The most alarming adverse events will be discussed in the following sections.

\section{Increased somnolence and attacks of sudden onset of sleep}

Sleep disturbances such as excessive daytime sleepiness (somnolence) and disorders of night time sleep patterns are common in PD and contribute to a general deterioration of the QOL (Tandberg et al 1998). Intuitively, increased somnolence should also be related to potentially fatal attacks of sudden onset of sleep while driving. Indeed, 75\% of PD patients reporting such attacks have high scores on the Epworth Sleepiness Scale (ESS) (Johns 1991). However, $25 \%$ of the patients have low scores on ESS, suggesting that sleep attacks may be a sleep phenomenon not necessarily related to increased somnolence (Paus et al 2003). There are contradictory reports on the role of pramipexole in the development of somnolence and attacks of sudden onset of sleep, and, being a cause of great concern, this issue will be discussed at large in this review.

The initial report by Frucht et al from 1999, on 8 PD patients treated with pramipexole who experienced sudden, irresistible attacks of sleep, and sustained motor vehicle accidents, led to a driving ban for pramipexole treated patients in some countries (Frucht et al 1999).

The following year Hauser et al reported data collected prior to Frucht's report. Six of 22 (27\%) PD patients randomized to pramipexole reported somnolence, compared with only 2 of 18 (11\%) placebo patients. In addition, during the open-label extension period, 21 of 37 (57\%) patients receiving pramipexole reported somnolence as an adverse event, 7 (19\%) reported falling asleep while driving, and $2(5 \%)$ reported minor motor vehicle accidents. Sleep latency normalized after withdrawal of pramipexole (Hauser et al 2000).

The 4-year results of the CALM-PD study showed that more somnolence was reported in the pramipexole group at 4 years, and while only 1 subject $(0.7 \%)$ in the levodopa group withdrew because of somnolence, 12 subjects ( $8 \%$ ) in the pramipexole group did that. Of these, 8 subjects $(66 \%)$ described their somnolence as "sudden" or "unexpected" and $5(41 \%)$ reported that these episodes occurred while driving. Two serious adverse events related to driving were reported in the levodopa group and 5 in the pramipexole group. Somnolence seemed to occur mostly during the escalation phase of pramipexole (Holloway et al 2004). A secondary analysis of this data found that initial treatment with pramipexole in patients with early PD almost doubled the risk for developing somnolence (Biglan et al 2007).

Etminan et al analyzed in two separate analyses the risk for somnolence in PD patients taking pramipexole and ropinirole vs placebo ( 4 trials) and patients taking these two DA as adjuvant therapy to levodopa ( 7 trials). They concluded that the risk for somnolence was higher with pramipexole or ropinirole both as monotherapy an as adjuvant to levodopa, compared with placebo or levodopa alone (Etminan et al 2001). Pramipexole gave a lower risk for somnolence and hypotension compared to ropinirole, but a greater risk for hallucinations (Etminan et al 2003).

Happe et al found that sedation in PD may be a class effect of DA, with no difference between ergot and non-ergot DA (Happe and Berger, 2001).

O'Suilleabhain et al reported 2002 on 368 PD patients treated with levodopa and DA, in monotherapy or in combination therapy (O'Suilleabhain and Dewey 2002). One hundred and seven patients took pramipexole. ESS was higher in PD as a group, compared with controls, and most of the increase could be accounted for by levodopa use, DA use, and PD severity. There was no significant difference between the DA, when controlling for levodopa dose, but there was a trend toward higher total ESS for those using pramipexole (12.2) and pergolide (12.8) compared with ropinirole (10.6) or bromocriptine (8).

Hobson et al surveyed 638 PD patients, including 420 drivers. Patients taking different DA and levodopa, in monotherapy or in combination, were compared with respect to attacks of sudden onset of sleep. Forty-nine drivers $(11.6 \%)$ reported such attacks. All medications and all combinations thereof could induce sudden onset of sleep, with the same risk in pramipexole users (13/143 or $9 \%)$ as in levodopa users (43/407 or $10.5 \%$ ). No statistically significant difference could be shown between the different DA, although the frequency of sudden sleep attacks was nominally highest in the ropinirole group (24/90 or $26 \%$ ) (Hobson et al 2002).

In addition, in a review article from the same year, Homann and colleagues identified 20 publications reporting sleep events in $124 \mathrm{PD}$ patients, including 32 on pramipexole, 84 on other DA, and 8 on levodopa monotherapy. Ninety six sleep attacks were identified. Overall, $6.6 \%$ of PD patients taking DA reported sleep events (range 0\%-30\%), without any difference among the different medications, making sleep events a class effect of all dopaminergic drugs. The frequency of road accidents in PD patients was not higher than in age 
matched controls, whether or not they were taking dopamine medication (Homann et al 2002).

Paus et al investigated 2592 PD patients, 284 of which were on a combination of pramipexole and levodopa therapy. Sudden sleep attacks were reported by 177 patients $(6 \%)$ on phone interviews. The frequency of sleep attacks was lowest for untreated PD patients (1.4\%), higher for levodopa monotherapy (2.9\%), DA monotherapy (5.3\%), combination therapy levodopa plus one DA (7.3\%), and it was highest for levodopa plus multiple DA therapy (9.2\%). For pramipexole plus levodopa therapy, the frequency of sleep attacks without warning signs was 5.6\% (95\% CI 4.3-7.0). There was no significant difference in this regard between pramipexole and the other DA (Paus et al 2003).

Similar results came from a study from 2005 on 929 patients, $39 \%$ of which used pramipexole, $18.5 \%$ ropinirole, 20\% levodopa alone, and the rest a combination of different antiparkinsonian drugs. After controlling for all available patient characteristics, there was a significant association between sudden uncontrollable somnolence and pramipexole therapy vs levodopa monotherapy (OR 2.22. 95\% CI 1.43-3.43). There was no significant difference in this regard between the other DA tested (ropinirole, pergolide, bromocriptine) and pramipexole. There was also a dose-response relationship for pramipexole, with high doses resulting in a higher risk for somnolence, compared with small to medium doses (OR 2.79 vs 2.08 respectively) (Avorn et al 2005).

Romigi et al investigated one single PD patient with polysomnography. They found an increase in both the diurnal and the nocturnal sleep under pramipexole plus levodopa vs cabergoline plus levodopa therapy. The ESS scorings showed mild sleepiness on pramipexole and levodopa therapy, but were normal on cabergoline and levodopa and on levodopa alone. The patient did experience sleep episodes and irresistible onset of daytime sleep, but no sleep attacks, and no sudden onset of daytime sleep, while on pramipexole and L-dopa therapy but not on other drug combinations. The authors conclude that there may exist an individual susceptibility to specific antiparkinsonian drugs with respect to sleepiness (Romigi et al 2005).

Razmy et al conducted a polysomnography study in PD patients treated with pramipexole, ropinirole, bromocriptine or pergolide, finding that the total dopaminergic drug dose given, rather than the specific DA used, was the best predictor of daytime sleepiness (Razmy et al 2004).

In conclusion, the available evidence shows that somnolence, while being part of PD itself, can be induced by all dopaminergic drugs, DA as well as levodopa itself. In addition, many other factors other than medication play an important role in this regard. Increased somnolence may be a risk factor for attacks with sudden onset of sleep, but sleep attacks can also occur without a prior increase in somnolence. The risk for increased somnolence is higher with DA, including pramipexole, compared with levodopa, but it seems to be similar in all DA, ergot, and non-ergot. Combination therapies increase the risk which is directly proportional with the total dose of dopaminergic equivalents. In the light of these findings, disabling somnolence can be reduced with monotherapy, preferably with levodopa only, by reducing the total dopaminergic doses, by improving the night sleep, and by finding alternative therapies. In the particular patient, switch to another DA may be attempted, as the susceptibility to particular DA may differ between patients. Modafinil treatment may be tried in difficult cases although the evidence supporting the use of modafinil in PD is conflicting (Nieves and Lang 2002; Adler et al 2003; Ondo et al 2005). Counseling is important for all patients treated with dopaminergic drugs, including pramipexole, and should include advice on night sleep hygiene, avoidance of sedatives and alcohol, normalizing diurnal rhythms, pulling over to stop if a wave of sleepiness is perceived. PD patients should abstain altogether from driving and other activities which require intense alertness, when suffering from generalized drowsiness, and if falling asleep during inactivity, regardless of their antiparkinsonian medication (Holloway et al 2004).

\section{Cardiac valvulopathy}

The recent finding that pergolide and cabergoline can cause cardiac valvulopathies led to a wave or research pertaining to valvular abnormalities in patients treated with non-ergot DA as well.

Peralta et al investigated 75 PD patients and controls with echocardiography. Twenty-five of the patients were treated with pramipexole. While the exposure to pergolide and cabergoline was associated with higher frequencies of valvular regurgitation compared to controls, that was not the case for the pramipexole treated patients, which showed about the same risk as controls, around 10\% (Peralta et al 2006).

One study from Japan comprising 16 pramipexole treated PD patients found a higher frequency of insignificant forms of valvulopathy in the pramipexole group (25\%) compared with the control group (17.6\%), although the difference was not statistically significant (OR 1.62 [0.45-5.87]). The authors 
point out that a similar frequency of valvulopathy was found in a normal-population study (Yamamoto et al 2006).

Zanettini et al included in their study 36 PD patients treated with pramipexole, none of which showed any clinical important valvular regurgitation (Zanettini et al 2007).

Junghanns et al evaluated 85 PD patients treated with ergot and non-ergot DA (23 on pramipexole) together with 38 age-matched controls. The frequencies of valvular heart disease were similar in the control group (37\%) and the pramipexole group (26\%) (Junghanns et al 2007).

In a large British case-study involving 11417 people who were prescribed drugs for PD, there were 31 patients with cardiac valve regurgitation, but none of them had been treated with pramipexole (Schade et al 2007).

Dewey et al included 21 pramipexole patients in their study comparing ergot (pergolide) and non-ergot DA (ropinirole and pramipexole) with respect to regurgitation. The conclusion was that the risk of cardiac valve regurgitation appeared to be low when using non - ergot-derived DA, much lower than for pergolide (Dewey et al 2007).

Thus, pramipexole does not seem to cause valvular abnormalities. These results are not unexpected as the cause of valvular fibrosis appears to be fibroblast activation mediated through the 5-HT2B serotonergic receptors (Rothman et al 2000). While cabergoline and pergolide are strong agonists at this receptor, pramipexole's affinity for the 5-HT2B receptor is low, which explains its low risk for cardiac valvulopathy, comparable with that seen in controls.

Still, Chaudhuri et al reported in 2004 in a letter to the Editors of the journal Movement Disorders that they were "aware of pramipexole being implicated as well, at least in one case" in respect with "fibrotic reaction with non-ergot agonists" (Chaudhuri et al 2004). As no further information is provided, this remark adds nothing to this discussion, and may even be confusing. However, it is included here for the sake of comprehensiveness.

In conclusion, although the evidence concerning pramipexole and valvulopathy is reassuring so far, continued pharmacovigilance is advisable.

\section{Impulse control disturbances}

Recently, pramipexole and other DA have been reported to cause impulse control disorders (ICD) such as gambling, compulsive buying, and pathological hypersexuality.

Dodd et al investigated 11 PD patients who had developed pathological gambling and other behavioral disorders. Eighty-two percent of these were treated with pramipexole, discontinuation of which led to improvement. In a literature survey, the authors found 17 similar case reports, 10 (59\%) of which were also treated with pramipexole, while the rest were taking other DA (Dodd et al 2005).

Klos et al reported on pathological hypersexuality in 13 PD patients, 6 of which were treated with pramipexole, and in 2 multiple-system atrophy (MSA) patients, 1 of whom was treated with pramipexole (Klos et al 2005). Several of these patients had other obsessive-compulsive behaviors in addition to hypersexuality. The conditions resolved after stopping pramipexole and/or adding antipsychotics. The authors identified 14 additional cases in the literature, all treated with levodopa plus DA, although the agonists were others than pramipexole. They suggest that excessive stimulation of the D2 receptor class and specifically the D3 receptor subclass may have caused this behavior.

Weintraub et al investigated the prevalence of ICD in 272 PD patients, half of which were treated with a DA (pramipexole, ropinirole, pergolide) (Weintraub et al 2006). Eighteen patients $(6.6 \%)$ met criteria for ICD at some point during their disease course and all of these were taking a DA while symptomatic. Pramipexole was the most frequently prescribed DA, representing more than half of all DA use. There was no difference between the three agonists in respect to their association with ICD and the authors concluded that the risk associated with ICD was a class effect of the DA and not specific to a certain agonist. The main risk for developing ICD in the context of DA treatment was a history of ICD symptoms prior to PD. A long term follow-up of 15 of these patients (mean time period 29 months) showed that $80 \%$ of them had discontinued or significantly reduced the DA treatment, and all these patients went into full or partial remission. However, most of these patients had increased the levodopa dosage, and the total levodopa equivalent daily dosage, as well as the UPDRS motor score, were similar at follow up. Of the three patients who had the same DA treatment at follow up, one was taking pramipexole. His compulsive sexuality had gone into full remission after DBS surgery and decreased amantadine dose (Mamikonyan et al 2008).

There is one case report of pathological gambling associated with pramipexole in a patient with restless legs syndrome (Quickfall and Suchowersky 2007).

In conclusion, according to several reports, there is a significant risk for developing ICD in patients treated with pramipexole and other DA. This risk seems to be a class effect and is not specific to pramipexole alone. In North America and also in many European countries, pramipexole is the most used DA, implying that more patients are exposed to it compared with the other agonists. This may lead to more 
reports on gambling and other behavioral disorders during pramipexole treatment, although the risk may be the same with other DA (Lu et al 2006).

\section{Hallucinations}

In studies on early PD, hallucinations occurred in $9 \%$ of pramipexole-treated patients, compared with $2.6 \%$ of patients on placebo. The same pattern was seen in advanced PD, with almost $17 \%$ of pramipexole treated patients developing hallucinations, compared with $3.8 \%$ in the placebo group. The development of hallucinations was one of the most common causes of study termination in patients with advanced PD ( $2.7 \%$ on pramipexole vs $0.4 \%$ on placebo) (Pinter et al 1999; Shannon et al 1997; Parkinson Study Group 2000; Mizuno et al 2003; Moller et al 2005). A meta-analysis found that, compared with placebo, pramipexole was associated with a higher risk for hallucinations than ropinirole (RR 5.2 [1.97-13.72] vs 2.75 [0.55-13.73]) (Etminan et al 2003).

The 4-year results of the CALM-PD study showed that while hallucinations were reported to be more common in the pramipexole group vs the levodopa group after 2 years, there was no significant difference at 4 years (Parkinson Study Group 2000; Holloway et al 2004; ). The risk for developing hallucinations was higher in younger patients initially treated with pramipexole, compared with younger patients initially treated with levodopa, but this was not seen in the older cohort. Cognitive disturbances, older age and greater comorbid illness were associated with more hallucinations (Biglan et al 2007).

In conclusion, there is an increased risk for hallucinations in PD patients treated with pramipexole.

\section{Edema}

Edema is a known adverse event associated with pramipexole treatment (Shannon et al 1997).

Tan and Ondo reported on 15 PD patients and 2 RLS patients who developed pedal edema, out of 300 patients treated with pramipexole. Edema abated after pramipexole discontinuation but it returned with reintroduction of pramipexole. Its intensity was dose dependent. No predisposing factors could be identified (Tan and Ondo 2000).

The 4-year results of the CALM-PD study showed that edema and cellulitis were later phenomena, reported more often in the pramipexole group. Five patients $(3.3 \%)$ in the pramipexole group withdrew because of edema, but none in the levodopa group (Holloway et al 2004).

In a retrospective medical record review, KleinerFisman et al found a $7.7 \%(95 \% \mathrm{CI}, 4.5 \%-12.9 \%)$ risk for development of pedal edema in the first year after initiation of pramipexole therapy in $237 \mathrm{PD}$ patients, with more rapid development of edema among those with a history of coronary artery disease. In total, $16 \%$ of all patients developed pedal edema, about the same prevalence as reported from the CALM-PD study (14.6\%) (Parkinson Study Group 2000). There was no relationship between dose of pramipexole and incidence and severity of pedal edema, and the edema resolved with withdrawal of pramipexole in $71 \%$ of cases (Kleiner-Fisman and Fisman 2007).

In a secondary analysis of the CALM-PD trial, Biglan et al showed that initial pramipexole treatment in patients with early PD therapy was associated with development of edema (HR 3.18, 95\% CI 1.95-5.18, p < 0.0001), together with female gender and comorbid cardiac disease. Edema occurred mostly after 2 years of treatment, and not initially, which may explain why previous studies did not report edema as a common complication (Biglan et al 2007).

In conclusion, pedal edema is a relatively common outcome in patients with $\mathrm{PD}$ receiving pramipexole, with a higher risk in patients with a history of cardiac disease.

\section{Conclusion: Pramipexole's place in the therapy of Parkinson's disease}

Pramipexole is generally well tolerated and efficacious in treating motor symptoms in both early and advanced PD. Its efficacy and tolerability are similar in African Americans, Asians, Caucasians and Hispanics. As initial treatment it may delay the onset of dyskinesias by delaying the start of levodopa therapy. It appears to have beneficial effects on non-motor symptoms such as depression, and it may improve treatment-resistant tremor, anhedonia and weight loss. Pramipexole seems to have neuroprotective effects in vitro and in animal models but these findings have not been replicated in humans. Compared with levodopa treatment, pramipexole therapy is associated with a higher risk for developing hallucinations, somnolence (and indirectly attacks of sudden onset of sleep), impulse control disturbances, peripheral edema, but not cardiac valvular disease. The risk for adverse events increases with patient age, pramipexole dose, severity of PD, concomitant combination therapy, and comorbidity, especially cardio-vascular. Continued pharmacovigilance in respect to adverse events, especially increased somnolence, cardiac valvulopathy, and psychiatric effects is necessary. Although pramipexole therapy is more costly than levodopa, the cost effectiveness increases over time due to a higher gain in QoL. More research is needed regarding pramipexole's neuroprotective potential and its impact on cognition, apathy, 
Table I Summary of the most important studies used for this review

\section{Clinical efficacy}

Monotherapy in early PD

Adjuvant therapy in advanced Parkinson's disease

Comparative studies

Drug-resistant tremor

Non-motor symptoms

Depression

(Lemke et al 2006. Rektorova et al 2003)

Anhedonia

(Lemke et al 2005. Lemke et al 2006.

Reichmann et al 2003)

Cognition

(Brusa et al 2003. Rektorova et al 2005.

Relja and Klepac, 2006)

Tolerability and adverse events

Increased somnolence and attacks of sudden

onset of sleep

Cardiac valvulopathy

Impulse control disturbances

Hallucinations

Edema
(Parkinson Study Group 1997, 2000. Shannon et al 1997. Holloway et al 2004)

(Lieberman et al 1997. Pinter et al 1999, 2000. Bennett and Piercey 1999.

Weiner et al 200I. Wong et al 2003. Moller et al 2005. Parkinson Study Group 2007)

Rotigotine: (Poewe et al 2007)

Bromocriptine: (Guttman 1997. Mizuno et al 2003) Pergolide: (Hanna et al 2001.

Rektorova et al 2003) Mixed: (Goetz et al 1999. Inzelberg et al 2000. Reichmann et al 2006)

(Pogarell et al 2002. Navan et al 2003a, b)

Apathy

(Guttman and Jaskolka 200I. Kumru et al 2006)

Weight loss

(Kumru et al 2006)

Rapid eye movement sleep behavior disorder

(Fantini et al 2003. Schmidt et al 2006)

(Frucht et al 1999. Hauser et al 2000. Happe and Berger 200I. Hobson et al 2002.

Homann et al 2002. O'Suilleabhain and Dewey 2002. Etminan et al 2003. Paus et al 2003.

Holloway et al 2004. Razmy et al 2004. Avorn et al 2005. Romigi et al 2005. Biglan et al 2007)

(Chaudhuri et al 2004. Junghanns et al 2007. Peralta et al 2006. Yamamoto et al 2006.

Dewey et al 2007. Schade et al 2007. Zanettini et al 2007)

(Dodd et al 2005. Klos et al 2005. Weintraub et al 2006. Quickfall and Suchowersky 2007.

Mamikonyan et al 2008)

(Shannon et al 1997. Pinter et al 1999. Parkinson Study Group 2000. Etminan et al 2003.

Mizuno et al 2003. Holloway et al 2004. Moller et al 2005. Biglan et al 2007)

(Parkinson Study Group 2000. Tan and Ondo 2000. Holloway et al 2004.

Kleiner-Fisman and Fisman 2007. Biglan et al 2007) fatigue, QoL, and treatment costs in PD. Pramipexole seems especially well suited for younger PD patients ( $<65$ years), without cognitive disturbances, with low comorbidity, at high risk for developing dyskinesias, and with particular PD features shown to be responsive to pramipexole.

\section{Limitations}

The literature search was limited to Medline. Although a lot of effort was made for identifying all publications related to every topic, there is always the risk that some publications have not been found. No publication judged to be relevant for this topic has been deliberately omitted. Table 1 offers a summary of the most important studies used for this review. No government agencies monitoring adverse events or pharmaceutical companies were contacted. This may bias the selection of publications.

\section{Disclosures}

Radu Constantinescu is a member of Boehringer-Ingelheim's Advisory Board in Sweden. This review was written without any financial support from Boehringer-Ingelheim or elsewhere. Between the end of 2005 and June 2006, Radu Constantinescu participated in the preparation of the "Efficacy of Pramipexole Taken Twice a Day in People with Early Parkinson's Disease" study.

\section{References}

Aarsland D, Larsen JP, Lim NG, et al. 1999. Range of neuropsychiatric disturbances in patients with Parkinson's disease. J Neurol Neurosurg Psychiatry, 67:492-6.

Aarsland D, Zaccai J, Brayne C. 2005. A systematic review of prevalence studies of dementia in Parkinson's disease. Mov Disord, 20:1255-63.

Adler CH, Caviness JN, Hentz JG, et al. 2003. Randomized trial of modafinil for treating subjective daytime sleepiness in patients with Parkinson's disease. Mov Disord, 18:287-93.

Ahlskog JE, Muenter MD. 2001. Frequency of levodopa-related dyskinesias and motor fluctuations as estimated from the cumulative literature. Mov Disord, 16:448-58.

Ahlskog JE, Muenter MD, Maraganore DM, et al. 1994. Fluctuating Parkinson's disease. Treatment with the long-acting dopamine agonist cabergoline. Arch Neurol, 51:1236-41.

Avorn J, Schneeweiss S, Sudarsky LR, et al. 2005. Sudden uncontrollable somnolence and medication use in Parkinson disease. Arch Neurol, 62:1242-8.

Bennett JP Jr, Piercey MF. 1999. Pramipexole - a new dopamine agonist for the treatment of Parkinson's disease. J Neurol Sci, 163:25-31.

Benton AH, Hamsher K. 1989. Multilingual aphasia examination manual. Iowa City, IA: University of Iowa. 
Biglan KM, Holloway RG Jr, McDermott MP, et al. 2007. Risk factors for somnolence, edema, and hallucinations in early Parkinson disease. Neurology, 69:187-95.

Bouthenet ML, Souil E, Martres MP, et al. 1991. Localization of dopamine D3 receptor mRNA in the rat brain using in situ hybridization histochemistry: comparison with dopamine D2 receptor mRNA. Brain Res, 564:203-19.

Brooks DJ, Abbott RJ, Lees AJ, et al. 1998. A placebo-controlled evaluation of ropinirole, a novel D2 agonist, as sole dopaminergic therapy in Parkinson's disease. Clin Neuropharmacol, 21:101-7.

Brusa L, Bassi A, Stefani A, et al. 2003. Pramipexole in comparison to 1-dopa: a neuropsychological study. J Neural Transm, 110:373-80.

Carvey PM, McGuire SO, Ling ZD. 2001. Neuroprotective effects of D3 dopamine receptor agonists. Parkinsonism Relat Disord, 7:213-223.

Cassarino DS, Fall CP, Smith TS, et al. 1998. Pramipexole reduces reactive oxygen species production in vivo and in vitro and inhibits the mitochondrial permeability transition produced by the parkinsonian neurotoxin methylpyridinium ion. $J$ Neurochem, 71:295-301.

Chaudhuri KR, Dhawan V, Basu S, et al. 2004. Valvular heart disease and fibrotic reactions may be related to ergot dopamine agonists, but nonergot agonists may also not be spared. Mov Disord, 19:1522-3.

Chen H, Zhang SM, Hernan MA, et al. 2003. Weight loss in Parkinson's disease. Ann Neurol, 53:676-9.

Constantinescu R, Romer M, McDermott MP, et al. 2007. Impact of pramipexole on the onset of levodopa-related dyskinesias. Mov Disord, 22: $1317-9$.

Corrigan MH, Denahan AQ, Wright CE, et al. 2000. Comparison of pramipexole, fluoxetine, and placebo in patients with major depression. Depress Anxiety, 11:58-65.

Cotzias GC, Papavasiliou PS, Tolosa E, et al. 1975. Aporphines in Parkinson's disease. Trans Am Neurol Assoc, 100:178-81.

Dewey RB 2nd, Reimold SC, O'Suilleabhain PE. 2007. Cardiac valve regurgitation with pergolide compared with nonergot agonists in Parkinson disease. Arch Neurol, 64:377-80.

Dodd ML, Klos KJ, Bower JH, et al. 2005. Pathological gambling caused by drugs used to treat Parkinson disease. Arch Neurol, 62:1377-81.

Dooneief G, Mirabello E, Bell K, et al. 1992. An estimate of the incidence of depression in idiopathic Parkinson's disease. Arch Neurol, 49:305-7.

Etminan M, Gill S, Samii A. 2003. Comparison of the risk of adverse events with pramipexole and ropinirole in patients with Parkinson's disease: a meta-analysis. Drug Saf, 26:439-44.

Etminan M, Samii A, Takkouche B, et al. 2001. Increased risk of somnolence with the new dopamine agonists in patients with Parkinson's disease: a meta-analysis of randomised controlled trials. Drug Saf, 24:863-8.

Fantini ML, Gagnon JF, Filipini D, et al. 2003. The effects of pramipexole in REM sleep behavior disorder. Neurology, 61:1418-20.

Frucht S, Rogers JD, Greene PE, et al. 1999. Falling asleep at the wheel: motor vehicle mishaps in persons taking pramipexole and ropinirole. Neurology, 52:1908-10.

Goetz CG, Blasucci L, Stebbins GT. 1999. Switching dopamine agonists in advanced Parkinson's disease: is rapid titration preferable to slow? Neurology, 52:1227-9.

Goldberg JF, Burdick KE, Endick CJ. 2004. Preliminary randomized, double-blind, placebo-controlled trial of pramipexole added to mood stabilizers for treatment-resistant bipolar depression. Am J Psychiatry, 161:564-6.

Gu M, Iravani MM, Cooper JM, et al. 2004. Pramipexole protects against apoptotic cell death by non-dopaminergic mechanisms. J Neurochem, 91:1075-81.

Guttman M. 1997. Double-blind comparison of pramipexole and bromocriptine treatment with placebo in advanced Parkinson's disease. International Pramipexole-Bromocriptine Study Group. Neurology, 49:1060-5.

Guttman M, Jaskolka J. 2001. The use of pramipexole in Parkinson's disease: are its actions D(3) mediated? Parkinsonism Relat Disord, $7: 231-4$.
Guttman M, Stewart D, Hussey D, et al. 2001. Influence of L-dopa and pramipexole on striatal dopamine transporter in early PD. Neurology, 56:1559-64

Hall ED, Andrus PK, Oostveen JA, et al. 1996. Neuroprotective effects of the dopamine D2/D3 agonist pramipexole against postischemic or methamphetamine-induced degeneration of nigrostriatal neurons. Brain Res, 742:80-8.

Hamilton M. 1960. A rating scale for depression. J Neurol Neurosurg Psychiatry, 23:56-62.

Hanna PA, Ratkos L, Ondo WG, et al. 2001. Switching from pergolide to pramipexole in patients with Parkinson's disease. J Neural Transm, 108:63-70.

Happe S, Berger K. 2001. The association of dopamine agonists with daytime sleepiness, sleep problems and quality of life in patients with Parkinson's disease - a prospective study. J Neurol, 248:1062-7.

Hauser RA, Gauger L, Anderson WM, et al. 2000. Pramipexole-induced somnolence and episodes of daytime sleep. Mov Disord, 15:658-63.

Hauser RA, McDermott MP, Messing S. 2006. Factors associated with the development of motor fluctuations and dyskinesias in Parkinson disease. Arch Neurol, 63:1756-60.

Hobson DE, Lang AE, Martin WR, et al. 2002. Excessive daytime sleepiness and sudden-onset sleep in Parkinson disease: a survey by the Canadian Movement Disorders Group. JAMA, 287:455-63.

Hoehn MM, Yahr MD. 1967. Parkinsonism: onset, progression and mortality. Neurology, 17:427-42.

Holloway RG, Shoulson I, Fahn S, et al. 2004. Pramipexole vs levodopa as initial treatment for Parkinson disease: a 4-year randomized controlled trial. Arch Neurol, 61:1044-53.

Holman AJ, Myers RR. 2005. A randomized, double-blind, placebocontrolled trial of pramipexole, a dopamine agonist, in patients with fibromyalgia receiving concomitant medications. Arthritis Rheum, 52:2495-505.

Homann CN, Wenzel K, Suppan K, et al. 2002. Sleep attacks in patients taking dopamine agonists: review. $B M J, 324: 1483-7$.

Häselbarth VF, Justus-Obenauer H, Peil H, et al. 1994a. Pharmacokinectics and bioavailability of pramipexole: Comparison of plasma levels after intravenous and oral administration in healthy volunteers (M/2730/0029). Upjohn Technical Report. 7215-94-016.

Häselbarth VK, Lohmann J, Justus-Obenauer H, et al. 1994b. Pharmacokinetics and metabolism of [14c]pramipexole after single intravenous and oral doses in healthy volunteers (Protocol M/2730/0030). Upjohn Technical Report. 7215-94-014.

Inzelberg R, Carasso RL, Schechtman E, et al. 2000. A comparison of dopamine agonists and catechol-O-methyltransferase inhibitors in Parkinson's disease. Clin Neuropharmacol, 23:262-6.

Inzelberg R, Schechtman E, Nisipeanu P. 2003. Cabergoline, pramipexole and ropinirole used as monotherapy in early Parkinson's disease: an evidence-based comparison. Drugs Aging, 20:847-55.

Izumi Y, Sawada H, Yamamoto N, et al. 2007. Novel neuroprotective mechanisms of pramipexole, an anti-Parkinson drug, against endogenous dopamine-mediated excitotoxicity. Eur J Pharmacol, 557:132-40.

Johns MW. 1991. A new method for measuring daytime sleepiness: the Epworth sleepiness scale. Sleep, 14:540-5.

Joyce JN, Woolsey C, Ryoo H, et al. 2004. Low dose pramipexole is neuroprotective in the MPTP mouse model of Parkinson's disease, and downregulates the dopamine transporter via the D3 receptor. $B M C$ Biol, 2:22

Junghanns S, Fuhrmann JT, Simonis G, et al. 2007. Valvular heart disease in Parkinson's disease patients treated with dopamine agonists: a reader-blinded monocenter echocardiography study. Mov Disord, 22:234-8

Karlsen KH, Tandberg E, Arsland D, et al. 2000. Health related quality of life in Parkinson's disease: a prospective longitudinal study. J Neurol Neurosurg Psychiatry, 69:584-9.

Kartzinel R, Teychenne P, Gillespie MM, et al. 1976. Bromocriptine and levodopa (with or without carbidopa) in parkinsonism. Lancet, $2: 272-5$. 
Kleiner-Fisman G, Fisman DN. 2007. Risk factors for the development of pedal edema in patients using pramipexole. Arch Neurol, 64:820-4.

Klos KJ, Bower JH, Josephs KA, et al. 2005. Pathological hypersexuality predominantly linked to adjuvant dopamine agonist therapy in Parkinson's disease and multiple system atrophy. Parkinsonism Relat Disord, 11:381-6.

Kompoliti K, Adler CH, Raman R, et al. 2002. Gender and pramipexole effects on levodopa pharmacokinetics and pharmacodynamics. Neurology, 58:1418-22.

Kumru H, Santamaria J, Valldeoriola F, et al. 2006. Increase in body weight after pramipexole treatment in Parkinson's disease. Mov Disord, $21: 1972-4$

Lang AF. 1989. Assessment of Parkinson's disease. In Munsat TL, ed. Quantification of Neurologic Deficit. Boston, Mass: ButterworthHeinemann. pp. 285-309.

Lattanzi L, Dell'Osso L, Cassano P, et al. 2002. Pramipexole in treatmentresistant depression: a 16-week naturalistic study. Bipolar Disord, 4:307-14.

Le WD, Jankovic J, Xie W, et al. 2000. Antioxidant property of pramipexole independent of dopamine receptor activation in neuroprotection. J Neural Transm, 107:1165-73.

Lemke MR, Brecht HM, Koester J, et al. 2005. Anhedonia, depression, and motor functioning in Parkinson's disease during treatment with pramipexole. J Neuropsychiatry Clin Neurosci, 17:214-20.

Lemke MR, Brecht HM, Koester J, et al. 2006. Effects of the dopamine agonist pramipexole on depression, anhedonia and motor functioning in Parkinson's disease. J Neurol Sci, 248:266-70.

Libman I, Gawel MJ, Riopelle RJ, et al. 1987. A comparison of bromocriptine (Parlodel) and levodopa-carbidopa (Sinemet) for treatment of "de novo" Parkinson's disease patients. Can J Neurol Sci, 14:576-80.

Lieberman A, Ranhosky A, Korts D. 1997. Clinical evaluation of pramipexole in advanced Parkinson's disease: results of a double-blind, placebocontrolled, parallel-group study. Neurology, 49:162-8.

Lorefalt B, Granerus AK, Unosson M. 2006. Avoidance of solid food in weight losing older patients with Parkinson's disease. J Clin Nurs, $15: 1404-12$.

Lu C, Bharmal A, Suchowersky O. 2006. Gambling and Parkinson disease. Arch Neurol, 63:298.

Mamikonyan E, Siderowf AD, Duda JE, et al. 2008. Long-term followup of impulse control disorders in Parkinson's disease. Mov Disord, 23:75-80.

Mierau J. 1995. Pramipexole: A dopamine-receptor agonist for treatment of Parkinson's Disease. Clin Neuropharmacol, 18(Suppl 1):S195-S206.

Mierau J, Schingnitz G. 1992. Biochemical and pharmacological studies on pramipexole, a potent and selective dopamine $\mathrm{D} 2$ receptor agonist. Eur J Pharmacol, 215:161-70.

Mierau J, Schneider FJ, Ensinger HA, et al. Pramipexole binding and activation of cloned and expressed dopamine D2, D3 and D4 receptors. Eur J Pharmacol, 1995. 290:29-36.

Mizuno Y, Yanagisawa N, Kuno S, et al. 2003. Randomized, double-blind study of pramipexole with placebo and bromocriptine in advanced Parkinson's disease. Mov Disord, 18:1149-56.

Moller JC, Oertel WH, Koster J, et al. 2005. Long-term efficacy and safety of pramipexole in advanced Parkinson's disease: results from a European multicenter trial. Mov Disord, 20:602-10.

Montgomery SA, Asberg M. 1979. A new depression scale designed to be sensitive to change. Br J Psychiatry, 134:382-9.

Montplaisir J, Nicolas A, Denesle R, et al. 1999. Restless legs syndrome improved by pramipexole: a double-blind randomized trial. Neurology, 52:938-43.

Navan P, Findley LJ, Jeffs JA, et al. 2003a. Double-blind, single-dose, cross-over study of the effects of pramipexole, pergolide, and placebo on rest tremor and UPDRS part III in Parkinson's disease. Mov Disord, 18:176-80.

Navan P, Findley LJ, Jeffs JA, et al. 2003b. Randomized, double-blind, 3-month parallel study of the effects of pramipexole, pergolide, and placebo on Parkinsonian tremor. Mov Disord, 18:1324-31.
Nieves AV, Lang AE. 2002. Treatment of excessive daytime sleepiness in patients with Parkinson's disease with modafinil. Clin Neuropharmacol, 25:111-4.

Noyes K, Dick AW, Holloway RG. 2004. Pramipexole v. levodopa as initial treatment for Parkinson's disease: a randomized clinical-economic trial. Med Decis Making, 24:472-85.

Noyes K, Dick AW, Holloway RG. 2005. Pramipexole and levodopa in early Parkinson's disease: dynamic changes in cost effectiveness. Pharmacoeconomics, 23:1257-70.

Noyes K, Dick AW, Holloway RG. 2006. Pramipexole versus levodopa in patients with early Parkinson's disease: effect on generic and diseasespecific quality of life. Value Health, 9:28-38.

O'Suilleabhain PE, Dewey RB Jr. 2002. Contributions of dopaminergic drugs and disease severity to daytime sleepiness in Parkinson disease. Arch Neurol, 59:986-9.

Ondo WG, Fayle R, Atassi F, et al. 2005. Modafinil for daytime somnolence in Parkinson's disease: double blind, placebo controlled parallel trial. J Neurol Neurosurg Psychiatry, 76:1636-9.

Pan T, Xie W, Jankovic J, et al. 2005. Biological effects of pramipexole on dopaminergic neuron-associated genes: relevance to neuroprotection Neurosci Lett, 377:106-9.

Parkinson Study Group. 1997. Safety and efficacy of pramipexole in early Parkinson disease. A randomized dose-ranging study. Parkinson Study Group. JAMA, 278:125-30.

Parkinson Study Group. 2000. Pramipexole vs levodopa as initial treatment for Parkinson disease: A randomized controlled trial. Parkinson Study Group. JAMA, 284:1931-8.

Parkinson Study Group. 2002. Dopamine transporter brain imaging to assess the effects of pramipexole vs levodopa on Parkinson disease progression. JAMA, 287:1653-61.

Parkinson Study Group. 2007. Pramipexole in levodopa-treated Parkinson disease patients of African, Asian, and Hispanic heritage. Clin Neuropharmacol, 30:72-85.

Paus S, Brecht HM, Koster J, et al. 2003. Sleep attacks, daytime sleepiness, and dopamine agonists in Parkinson's disease. Mov Disord, 18:659-67.

Peralta C, Wolf E, Alber H, et al. 2006. Valvular heart disease in Parkinson's disease vs. controls: An echocardiographic study. Mov Disord, 21:1109-13.

Pinter MM, Pogarell O, Oertel WH. 1999. Efficacy, safety, and tolerance of the non-ergoline dopamine agonist pramipexole in the treatment of advanced Parkinson's disease: a double blind, placebo controlled, randomised, multicentre study. J Neurol Neurosurg Psychiatry, 66:436-41.

Pinter MM, Rutgers AW, Hebenstreit E. 2000. An open-label, multicentre clinical trial to determine the levodopa dose-sparing capacity of pramipexole in patients with idiopathic Parkinson's disease. J Neural Transm, 107:1307-23.

Pizzagalli DA, Evins AE, Schetter EC, et al. 2008. Single dose of a dopamine agonist impairs reinforcement learning in humans: Behavioral evidence from a laboratory-based measure of reward responsiveness. Psychopharmacology, (Berl), 196:221-32.

Pluck GC, Brown RG. 2002. Apathy in Parkinson's disease. J Neurol Neurosurg Psychiatry, 73:636-42.

Poewe W, Hogl B. 2004. Akathisia, restless legs and periodic limb movements in sleep in Parkinson's disease. Neurology, 63:S12-6.

Poewe W, Wenning GK. 2000. Apomorphine: an underutilized therapy for Parkinson's disease. Mov Disord, 15:789-94.

Poewe WH, Rascol O, Quinn N, et al. 2007. Efficacy of pramipexole and transdermal rotigotine in advanced Parkinson's disease: a double-blind, double-dummy, randomised controlled trial. Lancet Neurol, 6:513-20.

Pogarell O, Gasser T, van Hilten JJ, et al. 2002. Pramipexole in patients with Parkinson's disease and marked drug resistant tremor: a randomised, double blind, placebo controlled multicentre study. J Neurol Neurosurg Psychiatry, 72:713-20.

Presgraves SP, Borwege S, Millan MJ, et al. 2004. Involvement of dopamine $\mathrm{D}(2) / \mathrm{D}(3)$ receptors and BDNF in the neuroprotective effects of S32504 and pramipexole against 1-methyl-4-phenylpyridinium in terminally differentiated SH-SY5Y cells. Exp Neurol, 190:157-70. 
Quickfall J, Suchowersky O. 2007. Pathological gambling associated with dopamine agonist use in restless legs syndrome. Parkinsonism Relat Disord, 13:535-6.

Ravina B, Eidelberg D, Ahlskog JE, Albin RL, Brooks DJ, Carbon M, et al. 2005. The role of radiotracer imaging in Parkinson disease. Neurology, 64:208-15.

Razmy A, Lang AE, Shapiro CM. 2004. Predictors of impaired daytime sleep and wakefulness in patients with Parkinson disease treated with older (ergot) vs newer (nonergot) dopamine agonists. Arch Neurol, 61:97-102.

Reichmann H, Brecht MH, Koster J, et al. 2003. Pramipexole in routine clinical practice: a prospective observational trial in Parkinson's disease. CNS Drugs, 17:965-73.

Reichmann H, Odin P, Brecht HM, et al. 2006. Changing dopamine agonist treatment in Parkinson's disease: experiences with switching to pramipexole. J Neural Transm Suppl, 17-25.

Reitan R. 1992. Trail making test. Manual for administration and scoring. South Tuscon: Reitan Neuropsychology Laboratory.

Rektorova I, Rektor I, Bares M, et al. 2003. Pramipexole and pergolide in the treatment of depression in Parkinson's disease: a national multicentre prospective randomized study. Eur J Neurol, 10:399-406.

Rektorova I, Rektor I, Bares M, et al. 2005. Cognitive performance in people with Parkinson's disease and mild or moderate depression: effects of dopamine agonists in an add-on to L-dopa therapy. Eur J Neurol, 12:9-15.

Relja M, Klepac N. 2006. A dopamine agonist, pramipexole, and cognitive functions in Parkinson's disease. J Neurol Sci, 248:251-4.

Rinne UK, Bracco F, Chouza C, et al. 1997. Cabergoline in the treatment of early Parkinson's disease: results of the first year of treatment in a double-blind comparison of cabergoline and levodopa. The PKDS009 Collaborative Study Group. Neurology, 48:363-8.

Romigi A, Brusa L, Marciani MG, et al. 2005. Sleep episodes and daytime somnolence as result of individual susceptibility to different dopaminergic drugs in a PD patient: a polysomnographic study. J Neurol Sci, 228:7-10.

Rothman RB, Baumann MH, Savage JE, et al. 2000. Evidence for possible involvement of 5-HT(2B) receptors in the cardiac valvulopathy associated with fenfluramine and other serotonergic medications. Circulation, 102:2836-41

Sayeed I, Parvez S, Winkler-Stuck K, et al. 2006. Patch clamp reveals powerful blockade of the mitochondrial permeability transition pore by the D2-receptor agonist pramipexole. FASEB J, 20:556-8.

Schade R, Andersohn F, Suissa S, et al. 2007. Dopamine agonists and the risk of cardiac-valve regurgitation. $N$ Engl J Med, 356:29-38.

Schifitto GF, Oakes D, Shulman LM, et al. R Fatigue in levodopa-naïve subjects with early Parkinson's disease, abstract at the First World Parkinson Congress, Washington DC, USA. 2006.

Schmidt MH, Koshal VB, Schmidt HS. 2006. Use of pramipexole in REM sleep behavior disorder: results from a case series. Sleep Med, 7:418-23.

Schrag A, Jahanshahi M, Quinn N. 2000. What contributes to quality of life in patients with Parkinson's disease? J Neurol Neurosurg Psychiatry, 69:308-12.

Scoyni RM, Aiello L, Trani I, et al. 2007. Drug adverse events and drop-out risk: a clinical case. Arch Gerontol Geriatr, 44(Suppl 1):359-64.

Shannon KM, Bennett JP Jr, Friedman JH. 1997. Efficacy of pramipexole, a novel dopamine agonist, as monotherapy in mild to moderate Parkinson's disease. The Pramipexole Study Group. Neurology, 49:724-8.
Shulman LM, Minagar A, Rabinstein A, et al. 2000. The use of dopamine agonists in very elderly patients with Parkinson's disease. Mov Disord, 15:664-8.

Snaith RP, Hamilton M, Morley S, et al. 1995. A scale for the assessment of hedonic tone the Snaith-Hamilton Pleasure Scale. Br J Psychiatry, 167:99-103.

Starkstein SE, Mayberg HS, Preziosi TJ, et al. 1992. Reliability, validity, and clinical correlates of apathy in Parkinson's disease. J Neuropsychiatry Clin Neurosci, 4:134-9.

Svensson K, Carlsson A, Huff RM, et al. 1994. Behavioral and neurochemical data suggest functional differences between dopamine D2 and D3 receptors. Eur J Pharmacol, 263:235-43.

Tan EK, Ondo W. 2000. Clinical characteristics of pramipexole-induced peripheral edema. Arch Neurol, 57:729-32.

Tandberg E, Larsen JP, Aarsland D, et al. 1996. The occurrence of depression in Parkinson's disease. A community-based study. Arch Neurol, 53:175-9.

Tandberg E, Larsen JP, Karlsen K. 1998. A community-based study of sleep disorders in patients with Parkinson's disease. Mov Disord, 13:895-9.

Toth MJ, Fishman PS, Poehlman ET. 1997. Free-living daily energy expenditure in patients with Parkinson's disease. Neurology, 48:88-91.

Uberti D, Bianchi I, Olivari L, et al. 2007. Pramipexole prevents neurotoxicity induced by oligomers of beta-amyloid. Eur J Pharmacol, 569:194-6.

Weiner WJ, Factor SA, Jankovic J, et al. 2001. The long-term safety and efficacy of pramipexole in advanced Parkinson's disease. Parkinsonism Relat Disord, 7:115-20.

Weintraub D, Morales KH, Moberg PJ, et al. 2005. Antidepressant studies in Parkinson's disease: a review and meta-analysis. Mov Disord, 20:1161-9.

Weintraub D, Siderowf AD, Potenza MN, et al. 2006. Association of dopamine agonist use with impulse control disorders in Parkinson disease. Arch Neurol, 63:969-73.

Wong KS, Lu CS, Shan DE, et al. 2003. Efficacy, safety, and tolerability of pramipexole in untreated and levodopa-treated patients with Parkinson's disease. J Neurol Sci, 216:81-7.

Wright CE, Sisson TL, Ichhpurani AK, et al. 1997. Steady-state pharmacokinetic properties of pramipexole in healthy volunteers. J Clin Pharmacol, 37:520-5.

Wynalda MA, Wienkers LC. 1997. Assessment of potential interactions between dopamine receptor agonists and various human cytochrome P450 enzymes using a simple in vitro inhibition screen. Drug Metab Dispos, 25:1211-4.

Yamamoto M, Uesugi T, Nakayama T. 2006. Dopamine agonists and cardiac valvulopathy in Parkinson disease: a case-control study. Neurology, 67:1225-9.

Zanettini R, Antonini A, Gatto G, et al. 2007. Valvular heart disease and the use of dopamine agonists for Parkinson's disease. N Engl J Med, 356:39-46.

Zou L, Jankovic J, Rowe DB, et al. 1999. Neuroprotection by pramipexole against dopamine- and levodopa-induced cytotoxicity. Life Sci, 64:1275-85.

Zung WW. 1965. A Self-Rating Depression Scale. Arch Gen Psychiatry, $12: 63-70$. 